NOVA

University of Newcastle Research Online

nova.newcastle.edu.au

Kouretzis, George P.; Bouckovalas, George D.; Gantes, Charis J. "3-D shell analysis of cylindrical underground structures under seismic shear (S) wave action" Soil Dynamics and Earthquake Engineering Vol. 26, Issue 10, p. 909-921 (2006)

Available from: http://dx.doi.org/10.1016/j.soildyn.2006.02.002

Accessed from: http://hdl.handle.net/1959.13/1056647 


\title{
3-D Shell Analysis of Cylindrical Underground Structures under Seismic Shear (S) Wave Action
}

\author{
George P. Kouretzis ${ }^{1}$, George D. Bouckovalas ${ }^{1 *}$ and Charis J. Gantes ${ }^{2}$ \\ ${ }^{1}$ Department of Geotechnical Engineering, ${ }^{2}$ Department of Structural Engineering, \\ Faculty of Civil Engineering, National Technical University of Athens, 9, Iroon Polytehniou Str., GR-15780, \\ Athens, Greece
}

The 3-D shell theory is employed in order to provide a new perspective to earthquake-induced strains in long cylindrical underground structures, when soil-structure interaction can be ignored. In this way, it is possible to derive analytical expressions for the distribution along the cross-section of axial, hoop and shear strains and also proceed to their consistent superposition in order to obtain the corresponding principal and von Mises strains. The resulting analytical solutions are verified against the results of 3-D dynamic FEM analyses. Seismic design strains are consequently established after optimization of the analytical solutions against the random angles which define the direction of wave propagation relative to the longitudinal structure axis, the direction of particle motion and the location on the structure cross-section. The basic approach is demonstrated herein for harmonic shear $(\mathrm{S})$ waves with plane front, propagating in a homogeneous half-space or in a two layer profile, where soft soil overlays the bedrock.

Keywords: earthquakes; pipelines; tunnels; shell theory; strain analysis, design.

\section{Introduction}

It is generally acknowledged that underground structures suffer less from earthquakes than buildings on the ground surface. However, recent earthquakes in Kobe (1995) [1, 2], Chi-Chi (1999) [3, 4, 5] and Düzce (1999) caused extensive failures in buried pipelines and tunnels, reviving the interest in the associated analysis and design methods.

In summary, most current analytical methodologies are based on two basic assumptions. The first is that the seismic excitation can be modeled as a train of harmonic waves with plane front, while the

\footnotetext{
${ }^{*}$ Corresponding author: George D. Bouckovalas, tel. +302107723870 , fax +302108068393

email address: gkouretz@central.ntua.gr
} 
second assumption states that inertia and kinematic interaction effects between the underground structure and the surrounding soil can be ignored. Theoretical arguments and numerical simulations plead for the general validity of the former statement regarding inertia effects [6], while the importance of kinematic interaction effects $[7,8]$ can be checked on a case-by-case basis via the flexibility index:

$F=\frac{2 E_{m}\left(1-v_{l}^{2}\right)(D / 2)^{3}}{E_{l}\left(1+v_{m}\right) t_{s}^{3}}$

where $E_{m}$ is the Young's modulus of the surrounding soil,

$E_{l}$ is the Young's modulus of the structure material,

$v_{m}$ is the Poisson's ratio of the surrounding soil,

$v_{l}$ is the Poisson's ratio of the structure material,

$t_{s}$ is the thickness of the cross-section, and

$D$ is the structure diameter

which is related to the ability of the lining to resist distortion from the ground [7, 9]. Values of the flexibility index higher than 20 are calculated for most common tunnels and pipelines, indicating that ignoring overall the soil-structure interaction is a sound engineering approach $[10,11]$.

Using the previous assumptions, Newmark [12] calculated axial strains due to longitudinal and bending deformation provoked by shear $(\mathrm{S})$ and compressional $(\mathrm{P})$ waves propagating parallel to the structure axis. Kuesel [13] and Yeh [14] extended the relations of Newmark to account for obliquely incident shear and Rayleigh waves, introducing the angle of wave propagation relative to the longitudinal structure axis as a random problem variable. Hoop and shear strains were addressed with considerable time lag relative to axial strains. Namely, more than a decade later, St John and Zahrah [15] presented analytical relations for these strain components, while Wang [7] underlined their importance relative to axial strains and proposed that the design of the tunnel lining should conform to the hoop strains resulting from $\mathrm{S}$ waves propagating transversely to the structure axis. 
Other, more advanced, analytical methodologies simulate soil-structure interaction effects, by employing the beam-on-elastic foundation approach [15] or modeling the underground structure as a cylindrical shell embedded in an elastic half-space [16-19], and account for slippage at the soilstructure interface [20, 21]. Furthermore, Manolis and Beskos [22] provide a comprehensive overview of numerical methods employed for detailed dynamic analyses of underground lifeline facilities [23-27], which can also take into account for the effect of the free ground surface on wave scattering, or complex soil stratification and non-linear behavior, at the expense of handiness. Nevertheless, the above analytical and numerical advancements are aimed at case-specific analyses, while current design guidelines $[6,28]$ suggest the use of simpler, Newmark and Kueseltype of analyses.

Concluding this brief state of the art review, it is pointed out that:

(a) The basic analytical solutions presented earlier, which form the basis of current design guidelines, compute essentially free-field strains and consequently transform them to peak axial, peak hoop and peak shear strain at specific points of the cross-section. However, the distribution of the above strains along the cross-section is not known and therefore a systematic structural analysis is not possible. Most importantly, as the locations of peak axial, hoop and shear strains do not coincide, it is not possible to superimpose the corresponding peak strains in order to obtain the overall maximum strain values (e.g. the principal or the von Mises strains), without being overconservative.

(b) A second simplification is that strains from shear waves, the most likely threat for underground structures, are computed for the special 2-D case, where the particle motion is parallel to the plane defined by the longitudinal axis of the structure and the direction of wave propagation. In this way, the random problem variables are reduced to the angle of seismic wave incidence, and the overall complexity of the analytical computations is minimized.

(c) Finally, published solutions concern uniform geological formations, and consequently it is not explicitly stated what ground parameters should be used for the computation of each strain component when a two layer system (e.g. soil over bedrock) is encountered. This uncertainty is 
reflected into current design guidelines. Namely, the design guidelines for underground pipelines $[6,28]$ call on seismological evidence to univocally suggest the use of an "apparent seismic wave velocity of the bedrock", at least equal to $2000 \mathrm{~m} / \mathrm{s}$, for the computation of axial strains, regardless of local soil conditions. On the other hand, the design guidelines for tunnels in soil provided by Wang [7] give head to hoop strains due to vertically propagating shear (S) waves, and suggest the use of the seismic wave velocity of the soil rather than that of the bedrock.

Seeking a new perspective to the problem, the 3-D shell theory has been used for a consistent calculation of the normal (axial and hoop) and the shear strain distribution over the entire crosssection of a cylindrical underground structure, as well as the resulting principal and von Mises strains. Due to the relative complexity of the mathematics, the resulting relations are verified against results from dynamic Finite Element analyses.

To preserve the length limits of the presentation, the basic methodology and the findings of this study are demonstrated herein for the generic case of shear (S) waves propagating at a random direction relative to the structure axis (Fig. 1). It is common practice to analyze such waves vectorially into two specific components: (a) an SV wave with particle motion perpendicular to the plane formed by the direction of wave propagation and the longitudinal structure axis, and (b) an SH wave with particle motion parallel to the aforementioned plane. Thus, strains from randomly oriented SH and SV seismic waves are addressed separately, and consequently superimposed to give the overall strains. The detailed derivation is provided for the case of uniform ground. The case of underground structures in a soil layer overlaying the bedrock is examined next, as a variation of the above basic case.

\section{Strains from SH-waves in uniform ground}

To aid the following presentation, Figure 2 defines the strains that are considered in the analysis of thin cylindrical shells (membranes), namely:

$$
\varepsilon_{\alpha}=\varepsilon_{z}=\frac{\partial u_{z}}{\partial z} \quad \text { (axial strain) }
$$


$\varepsilon_{h}=\varepsilon_{\theta \theta}=\frac{1}{r} \frac{\partial u_{\theta}}{\partial \theta}+\frac{u_{r}}{r} \quad$ (hoop strain)

$\gamma=\gamma_{\theta z}=\frac{1}{r} \frac{\partial u_{z}}{\partial \theta}+\frac{\partial u_{\theta}}{\partial z} \quad$ (shear strain)

where $u_{z}, u_{r}$ and $u_{\theta}$ are the displacement components imposed by the shear wave, in a cylindrical coordinate system fitted to the longitudinal axis of the structure. Due to the small thickness of the cross-section, the remaining three strain components (one radial and two shear), are customarily neglected as they are fairly insignificant.

For an $\mathrm{SH}$ wave propagating in a direction $z^{\prime}$ which forms an angle $\varphi$ with the $z$ axis of the structure (Fig. 3), the displacement field is described as:

$u_{x^{\prime}}=A_{\max } \cos \beta \sin \left[\frac{2 \pi}{L}\left(z^{\prime}-C t\right)\right]$

$u_{y^{\prime}}=0$

$u_{z^{\prime}}=0$

where $\beta$ is the angle between the particle velocity vector and the propagation plane, $A_{\max }$ is the peak particle displacement of the seismic motion, $C$ is the shear wave propagation velocity, $L$ is the wavelength and $t$ stands for time. As initially introduced by Kuesel [13], propagation of an SH wave at an angle $\varphi$ relative to the structure axis is equivalent in terms of strains to the following apparent waves:

- An SH wave propagating along the structure axis, with wavelength $L / \cos \varphi$, propagation velocity $C / \cos \varphi$ and maximum amplitude $A_{\max } \cos \beta \cos \varphi$.

- A P wave propagating along the structure axis, with wavelength $L / \cos \varphi$, propagation velocity $C / \cos \varphi$ and maximum amplitude $-A_{\max } \cos \beta \sin \varphi$.

- A P wave propagating transversely to the structure axis, with wavelength $L / \sin \varphi$, propagation velocity $C / \sin \varphi$ and maximum amplitude $A_{\max } \cos \beta \cos \varphi$.

- An SH wave propagating transversely to the structure axis, with wavelength $L / \sin \varphi$, propagation velocity $C / \sin \varphi$ and maximum amplitude $A_{\max } \cos \beta \sin \varphi$. 
Thus, strains may be computed separately for each one of these apparent waves and consequently superimposed.

Apparent SH wave propagating along the axis of the structure._Let us consider the Cartesian coordinate system of Figure 3, and an axially propagating $\mathrm{SH}$ wave inducing motion in the $x z$ plane. For harmonic waves with plane front, ground motion can be described as:

$u_{x}=A_{\max } \cos \beta \cos \phi \sin \left[\frac{2 \pi}{L / \cos \phi}\left(z-\frac{C}{\cos \phi} t\right)\right]$

In a cylindrical coordinate system fitted to the longitudinal axis of the structure (Fig. 4a), ground displacement can be decomposed into the following radial and tangential components:

$$
\begin{aligned}
& u_{r}=A_{\max } \cos \beta \cos \phi \sin \theta \sin \left[\frac{2 \pi}{L / \cos \phi}\left(z-\frac{C}{\cos \phi} t\right)\right] \\
& u_{\theta}=A_{\max } \cos \beta \cos \phi \cos \theta \sin \left[\frac{2 \pi}{L / \cos \phi}\left(z-\frac{C}{\cos \phi} t\right)\right]
\end{aligned}
$$

According to the "thin shell" theory adopted herein, as well as Eqs. 2 to 4, the above displacement field results in pure shear strain (i.e. $\varepsilon_{\alpha}=\varepsilon_{h}=0$ ) with amplitude:

$$
\gamma=\frac{V_{\max } \cos \beta}{C} \cdot \cos ^{2} \phi \cdot \cos \theta
$$

where $V_{\max }=\frac{2 \pi A_{\max }}{L} \cdot C$ is the peak particle velocity of the harmonic shear wave.

In the above derivation, the relative displacement at the soil-structure interface $u_{z}$ is considered to be zero, implying that the shell is "rough" and does not permit slippage to occur (Fig. 5a). If the shell is "smooth", i.e. it is free to slip over the surrounding soil, then $\gamma=0$ and according to Eq. 2 an axial displacement will emerge (Fig. 5b), that is equal to:

$$
u_{z}=-x \frac{\partial u_{x}}{\partial z}
$$

or, 
$u_{z}=-r \sin \theta \cdot \frac{2 \pi A_{\max } \cos \beta \cos ^{2} \phi}{C} \cdot \cos \left[\frac{2 \pi}{L / \cos \phi}\left(z-\frac{C}{\cos \phi} t\right)\right]$

Hence, shear strain $\gamma$ will now give its place to an axial strain with amplitude equal to:

$\varepsilon_{\alpha}=r \sin \theta \cdot \frac{a_{\max } \cdot \cos \beta}{C^{2}} \cos ^{3} \phi$

where $a_{\max }=\left(\frac{2 \pi}{L} C\right)^{2} A_{\max }$ is the peak ground acceleration.

Note first that the two interface models examined previously, which are shown schematically in Figure 5, cannot physically co-exist and consequently the above axial and shear strains should not be superimposed. In addition, the axial strain corresponding to the "smooth" interface model is roughly one order of magnitude less than the shear and principal strains $\left(\varepsilon_{1,3}=\underline{+} / 2\right)$ corresponding to the "rough" interface model. Thus, in extent of these observations, the "rough" interface assumption will be adopted hereafter as more conservative.

Apparent $\mathbf{P}$ wave propagating along the axis of the structure._ In the coordinate system of Figure $4 \mathrm{a}$, the harmonic displacement induced to the shell by an axially propagating $\mathrm{P}$ wave can be expressed as:

$u_{z}=-A_{\max } \cos \beta \sin \phi \sin \left[\frac{2 \pi}{L / \cos \phi}\left(z-\frac{C}{\cos \phi} t\right)\right]$

According to Eqs. 4 to 6 , this displacement will merely cause axial strain (i.e. $\varepsilon_{h}=\gamma=0$ ), with amplitude:

$\varepsilon_{a}=-\frac{V_{\max } \cos \beta}{C} \cdot \sin \phi \cdot \cos \phi$

Apparent $P$ wave propagating transversely relatively to the axis of the structure._ This apparent wave will enforce a harmonic displacement on the shell that is expressed as:

$u_{x}=A_{\max } \cos \beta \cos \phi \sin \left[\frac{2 \pi}{L / \sin \phi}\left(x-\frac{C}{\sin \phi} t\right)\right]$ 
The vectorial analysis of $u_{x}$ to the cylindrical coordinate system of Figure 4a yields the following displacement components in the radial and tangential directions:

$$
\begin{aligned}
& u_{r}=A_{\max } \cos \beta \cos \phi \sin \theta \sin \left[\frac{2 \pi}{L / \sin \phi}\left(x-\frac{C}{\sin \phi} t\right)\right] \\
& u_{\theta}=A_{\max } \cos \beta \cos \phi \cos \theta \sin \left[\frac{2 \pi}{L / \sin \phi}\left(x-\frac{C}{\sin \phi} t\right)\right]
\end{aligned}
$$

In this case, only hoop strain will develop, with amplitude equal to:

$$
\varepsilon_{h}=\frac{V_{\max } \cdot \cos \beta}{C} \cdot \sin \phi \cos \phi \cdot \cos ^{2} \theta
$$

as the axial and shear strain components resulting from Eqs. 2 and 4 become zero (i.e. $\varepsilon_{\alpha}=\gamma=0$ ).

Apparent SH wave propagating transversely relatively to the axis of the structure._ The propagation of a transverse $\mathrm{SH}$ wave induces the following harmonic axial displacement on the structure:

$$
u_{z}=-A_{\max } \cos \beta \sin \phi \sin \left[\frac{2 \pi}{L / \sin \phi}\left(x-\frac{C}{\sin \phi} t\right)\right]
$$

which, according to Eqs. 2 to 4, gives shear strain amplitude:

$$
\gamma=-\frac{V_{\max } \cos \beta}{C} \cdot \sin ^{2} \phi \cdot \cos \theta
$$

and $\varepsilon_{\alpha}=\varepsilon_{h}=0$.

\section{Strains from SV-waves in uniform ground}

In Cartesian coordinates, a shear SV wave propagating along $z^{\prime}$, at an angle $\varphi$ relatively to the axis $z$ of the structure (Fig. 3), induces the following displacement field:

$$
\begin{aligned}
& u_{x^{\prime}}=0 \\
& u_{y^{\prime}}=A_{\max } \sin \beta \sin \left[\frac{2 \pi}{L}\left(z^{\prime}-C t\right)\right] \\
& u_{z^{\prime}}=0
\end{aligned}
$$


In terms of displacement, this wave can be decomposed to the following apparent waves:

- An SV wave propagating along the structure axis $z$, with wavelength $L / \cos \varphi$, propagation velocity $C / \cos \varphi$ and maximum amplitude $A_{\max } \sin \beta$.

- An SV wave propagating transverse to the structure axis, with wavelength $L / \sin \varphi$, propagation velocity $C / \sin \varphi$ and maximum amplitude $A_{\max } \sin \beta$.

Apparent SV wave propagating along the axis of the structure._ The displacement applied to the structure by its surrounding medium is equal to:

$u_{y}=A_{\max } \sin \beta \sin \left[\frac{2 \pi}{L / \cos \phi}\left(z-\frac{C}{\cos \phi} t\right)\right]$

or, in the cylindrical coordinate system of Figure $4 b$ :

$u_{r}=A_{\max } \sin \beta \cos \theta \sin \left[\frac{2 \pi}{L / \cos \phi}\left(z-\frac{C}{\cos \phi} t\right)\right]$

$u_{\theta}=A_{\max } \sin \beta \sin \theta \sin \left[\frac{2 \pi}{L / \cos \phi}\left(z-\frac{C}{\cos \phi} t\right)\right]$

According to the strain definitions provided earlier (Eqs. 2 to 4), the above displacements result in pure shear strain on the shell, with amplitude equal to:

$\gamma=\frac{V_{\max } \sin \beta}{C} \cdot \cos \phi \cdot \sin \theta$

while the corresponding axial and hoop strain components become zero (i.e. $\varepsilon_{\alpha}=\varepsilon_{h}=0$ ).

Apparent SV wave propagating transversely relatively to the axis of the structure.- The corresponding displacement $u_{y}$ is now:

$u_{y}=A_{\max } \sin \beta \sin \left[\frac{2 \pi}{L / \sin \phi}\left(x-\frac{C}{\sin \phi} t\right)\right]$

which can be decomposed in the cylindrical coordinate system of Figure $4 \mathrm{~b}$, to: 


$$
\begin{aligned}
& u_{r}=A_{\max } \sin \beta \cos \theta \sin \left[\frac{2 \pi}{L / \sin \phi}\left(r \sin \theta-\frac{C}{\sin \phi} t\right)\right] \\
& u_{\theta}=-A_{\max } \sin \beta \sin \theta \sin \left[\frac{2 \pi}{L / \sin \phi}\left(r \sin \theta-\frac{C}{\sin \phi} t\right)\right]
\end{aligned}
$$

In this case, the axial and shear strain components become zero (i.e. $\varepsilon_{\alpha}=\gamma=0$ ) while the remaining hoop strain amplitude is:

$$
\varepsilon_{h}=\frac{V_{\max } \cdot \sin \beta}{2 C} \cdot \sin \phi \cdot \sin 2 \theta
$$

The strain amplitudes derived herein for the SV waves are in phase and can be added algebraically to the corresponding ones derived earlier for the SH waves. Thus, the expressions for the amplitude of total structure strains in uniform ground become:

$$
\begin{aligned}
& \varepsilon_{a}=-\frac{V_{\max }}{2 C} \cos \beta \cdot \sin 2 \phi \\
& \varepsilon_{h}=\frac{V_{\max }}{2 C}\left(\cos \beta \cdot \sin 2 \phi \cdot \cos ^{2} \theta+\sin \beta \cdot \sin \phi \cdot \sin 2 \theta\right) \\
& \gamma=\frac{V_{\max }}{C}(\cos \beta \cdot \cos 2 \phi \cdot \cos \theta+\sin \beta \cdot \cos \phi \cdot \sin \theta)
\end{aligned}
$$

where angles $\varphi, \theta$ and $\beta$ are defined in Figs. 1, 3 and 4.

\section{Soft soil effects}

Consider the case of an S wave propagating in a two-layered half-space, consisting of a soft soil layer overlying the semi-infinite bedrock (Fig. 6). According to Snell's law, the angle of wave propagation in soil $\alpha_{S}$ is related to the angle of wave propagation in rock $\alpha_{R}$ as:

$$
\cos \alpha_{S}=\cos \alpha_{R} \frac{C_{S}}{C_{R}}
$$

where $C_{R}$ is the shear wave propagation velocity in the bedrock and $C_{S}$ is the shear wave propagation in the soft soil layer. In the following presentation we neglect the $\mathrm{P}$ wave resulting from the refraction of the SV component of the $\mathrm{S}$ wave at the soil-bedrock interface. This 
assumption draws upon the fact that $\mathrm{P}$ waves propagate with a velocity that is substantially larger than that of S waves, and therefore both waves do not arrive simultaneously at the structure.

According to the apparent wave concept presented before, the propagation of a shear wave from the bedrock to the ground surface through the soft soil layer is equivalent in terms of strains with the following apparent waves (Fig. 6):

- An apparent wave propagating vertically, with wavelength $L_{S} / s i n a_{S}$ and propagation velocity $C_{S} / \operatorname{sina}_{S}$

- An apparent wave propagating horizontally, with wavelength $L_{S} / \cos a_{S}$ and propagation velocity $C_{S} / \cos a_{S}$

We can rewrite the wavelength of the horizontal apparent wave with the aid of Eq. 37, as:

$L_{S} / \cos a_{S}=\frac{L_{R}\left(C_{S} / C_{R}\right)}{\cos a_{R}\left(C_{S} / C_{R}\right)}=L_{R} / \cos a_{R}$

i.e. the horizontal apparent wave at the ground surface propagates with the same velocity and has the same wavelength as the apparent wave formed due to the time lag of waves impinging at the soft soil-bedrock interface (Fig. 6).

Moreover, it is:

$\sin a_{S}=\sqrt{1-\cos ^{2} a_{S}}=\sqrt{1-\cos ^{2} a_{R}\left(\frac{C_{S}}{C_{R}}\right)^{2}}$

Figure 7 draws the variation of $\sin \alpha_{S}$ with the angle $\alpha_{R}$, for different values of the $C_{S} / C_{R}$ ratio. Observe that for $C_{S} / C_{R}=1 / 3$ we can reasonably assume that $\sin \alpha_{S} \cong 1$. This implies that the vertical apparent wave propagates in the soft soil layer with velocity and wavelength that are more or less equal to the shear wave propagation velocity and wavelength in soft soil, $C_{S}$ and $L_{S}$ respectively.

In the following, strains due to vertical and horizontal apparent waves are computed separately, using the expressions for the generic case of uniform ground and consequently superimposed to provide total strains. 
The vertically propagating apparent $\mathbf{S}$ wave impinges at the structure axis with an angle of incidence $\phi^{V}=\frac{\pi}{2}$, while the particle motion forms a random angle $\beta^{V}$ with the vertical plane passing through the structure axis. Substituting these angles in Eqs. 34 to 36 for uniform ground yields:

$\varepsilon_{a}=0$

$\varepsilon_{h}=\frac{V_{\max }}{2 C_{S}} \sin \beta^{V} \cdot \sin 2 \theta^{V}$

$\gamma=-\frac{V_{\max }}{C_{S}} \cos \beta^{V} \cdot \cos \theta^{V}$

where $\theta^{V}$ is the polar angle in the cross-section.

The horizontally propagating apparent $\mathbf{S}$ wave impinges at the structure axis at a random angle $\varphi^{H}$, with the particle motion forming an angle $\beta^{H}=\frac{\pi}{2}-\alpha_{S}$ with the horizontal plane, while $\theta^{\mathrm{H}}=\theta^{V}-\frac{\pi}{2}$ is the polar angle in the cross-section. In this case, Eqs. 34 to 36 for uniform ground give:

$$
\begin{aligned}
& \varepsilon_{a}=-\frac{V_{\max }}{2 C_{R}} \cdot \cos \alpha_{R} \sin 2 \phi^{H} \\
& \varepsilon_{h}=\frac{V_{\max }}{2 C_{R}}\left(\cos \alpha_{R} \cdot \sin 2 \phi^{H} \cdot \cos ^{2} \theta^{H}-\frac{C_{S}}{C_{R}} \cdot \cos ^{2} \alpha_{R} \cdot \sin \phi^{H} \cdot \cos 2 \theta^{H}\right) \\
& \gamma=\frac{V_{\max }}{C_{R}}\left(\cos \alpha_{R} \cdot \cos 2 \phi^{H} \cdot \cos \theta^{H}+\frac{C_{S}}{C_{R}} \cos ^{2} \alpha_{R} \cdot \cos \phi^{H} \cdot \sin \theta^{H}\right)
\end{aligned}
$$

Adding of the above (in phase) strain amplitudes, from the apparent vertically and horizontally propagating waves, leads to the following expressions for the total strain amplitudes:

$$
\begin{aligned}
& \varepsilon_{a}=-\frac{V_{\max }}{C_{S}}\left(\frac{C_{S}}{C_{R}} \cos \alpha_{R} \sin 2 \phi^{*}\right) \\
& \varepsilon_{h}=\frac{V_{\max }}{2 C_{S}}\left(\sin \beta^{*} \sin 2 \theta^{*}+\frac{C_{S}}{C_{R}} \cdot \cos \alpha_{R} \cdot \sin 2 \phi^{*} \cdot \sin ^{2} \theta^{*}-\left(\frac{C_{S}}{C_{R}}\right)^{2} \cdot \cos ^{2} \alpha_{R} \cdot \sin \phi^{*} \cdot \sin 2 \theta^{*}\right)
\end{aligned}
$$


$\gamma=\frac{V_{\max }}{C_{S}}\left(-\cos \beta^{*} \cdot \cos \theta^{*}+\frac{C_{S}}{C_{R}} \cdot \cos \alpha_{R} \cdot \cos 2 \phi^{*} \cdot \sin \theta^{*}-\left(\frac{C_{S}}{C_{R}}\right)^{2} \cos ^{2} \alpha_{R} \cdot \cos \phi^{*} \cdot \cos \theta^{*}\right)$

where $\theta^{*}=\theta^{V}=\theta^{H}+\frac{\pi}{2}, \beta^{*}=\beta^{V}$, and $\phi^{*}=\phi^{\mathrm{H}}$

\section{Numerical verification}

Validation of the above analytical relations for uniform ground, as well as for soft soil over bedrock, is accomplished through comparison with numerical results from elastic 3-D dynamic analyses, performed with the aid of the commercial FEM program ANSYS [29]. It is clarified in advance that the aim of this comparison is not to check the validity of the assumptions but merely to check the complex mathematics that underlay the present computation of shell strains.

Uniform Ground Conditions.- Figure 8 illustrates the geometry that was analyzed and the associated ground motion. Namely, the underground structure is modeled as 3-D hollow cylinder with $30 \mathrm{~m}$ length, $1 \mathrm{~m}$ diameter and $0.002 \mathrm{~m}$ wall thickness. It is discretized into 16 equal shell elements per cross-section, each of 1m length, using the SHELL63 element [29] that has both membrane and bending capabilities. The structure material is considered to be isotropic linear elastic with specific weight $\gamma_{l}=75 \mathrm{KN} / \mathrm{m} 3$, Young's modulus $E_{l}=210 \mathrm{GPa}$ and Poisson's ratio of $v_{l}=0$. Note that the exact values of $\gamma_{l}, E_{l}$ and $v_{l}$ are of absolutely no importance to the numerical results, as seismic strain components $\varepsilon_{\alpha}, \varepsilon_{h}$ and $\gamma$ are directly related to imposed displacements alone (Eqs. 2-4). As the underground structure conforms to the ground motion, the displacements of each node were set equal to the corresponding ground displacement. The ground motion is harmonic with unit amplitude, featuring a propagation velocity of $C=100 \mathrm{~m} / \mathrm{sec}$, a period of $T=0.1 \mathrm{sec}$ and a propagation direction that forms an angle $\varphi=30^{\circ}$ with the structure axis. Thus, to apply the ground displacements correctly, a global coordinate system rotated by $30^{\circ}$ relatively to the structure axis was used, and the following dynamic displacement boundary conditions were applied on each shell node:

$u_{y^{\prime}, i}=A_{\max } \sin \beta \sin \left[\frac{2 \pi}{L}\left(z_{i}^{\prime}-C t\right)\right]$ 
$u_{z^{\prime}, i}=A_{\max } \cos \beta \sin \left[\frac{2 \pi}{L}\left(z_{i}^{\prime}-C t\right)\right]$

$u_{y^{\prime}, i}=\theta_{x^{\prime}, i}=\theta_{y^{\prime}, i}=\theta_{z^{\prime}, i}=0$

with $A_{\max }=1.0$ and the random angle $\beta$ considered to be $75^{\circ}$.

The boundary conditions described above imply that, as in the analytical solution, the shell fully conforms to the ground motion and, consequently, that kinematic and inertia soil-structure interaction effects are ignored. The buildup of ground motion is gradual (Fig. 8), using a transition time interval equal to 8 wave periods, so as numerical pseudo-oscillations from the sudden application of a large amplitude displacement are avoided. The above displacements are not synchronous at all nodes; supposing that the wave front reaches $z=0$ at $t=0$, it will arrive at nodes with $z_{i} \neq 0$ with a time lag of $t_{i}=z_{i} /(C / \cos \varphi)$. Applied displacements are zero before that time instant.

Figure 9 compares analytical with numerical strain amplitude predictions. Absolute rather than algebraic values of strains are presented in order to simplify the comparison. It may be observed that the analytical predictions match not only the peak values but also the distribution of strain amplitudes over the entire cross-section of the shell.

Soft Soil over Bedrock.- An 3-D shell, identical to the one used in the uniform ground analysis presented above (Fig. 8), is now considered to rest within a soft soil layer with $C_{S}=100 \mathrm{~m} / \mathrm{sec}$, overlying the seismic bedrock that features a shear wave propagation velocity of $C_{R}=365 \mathrm{~m} / \mathrm{sec}$. The seismic waves are assumed to impinge at the soil-bedrock interface with an angle $\alpha_{R}=20^{\circ}$ so that, according to Eq. 37, the angle of wave propagation in the soft soil layer will be $\alpha_{S}=75^{\circ}$. To describe the propagation of the refracted shear wave in the soft soil layer, a rotated coordinate system has to be defined, as before: The axis $z^{\prime}$ of the new coordinate system is rotated relatively to the undeformed axis of the structure $z$ (Fig. 8) by an Eulerian angle $\theta_{y z}=-\alpha_{S}=-75^{\circ}$ and the axis $\mathrm{x}^{\prime}$ relatively to the original axis $x$ by $\theta_{x y}=\varphi^{*}=30^{\circ}$, where $\varphi^{*}$ is the random angle formed by the axis of the structure and the vertical plane defined by the propagation path. In this rotated coordinate system, the displacement field resulting from the harmonic wave propagation can be analytically described as: 


$$
\begin{aligned}
& u_{x^{\prime}, i}=A_{\max } \sin \beta^{*} \sin \left[\frac{2 \pi}{L}\left(z_{i}^{\prime}-C_{S} t\right)\right] \\
& u_{y^{\prime}, i}=A_{\max } \cos \beta^{*} \sin \left[\frac{2 \pi}{L}\left(z_{i}^{\prime}-C_{S} t\right)\right] \\
& u_{z^{\prime}, i}=\theta_{x^{\prime}, i}=\theta_{y^{\prime}, i}=\theta_{z^{\prime}, i}=0
\end{aligned}
$$

where the amplitude of the shear wave in the soft soil layer is $A_{\max }=1.0$, the wavelength is $L=10 \mathrm{~m}$ and the random angle of the particle motion relatively to the propagation plane $z^{\prime} y^{\prime}$ of the refracted wave is taken as $\beta^{*}=60^{\circ}$.

As in the previous case of uniform ground, the above displacements are not synchronous at all nodes. Supposing that the wave front reaches $z^{\prime}=0$ at $t=0$, it will arrive at nodes with $z_{i}^{\prime} \neq 0$ with a time lag of $t_{i}=z_{i}^{\prime} / C_{S}$, while applied displacements are zero before that time instant. Again the buildup of ground motion is gradual (Fig. 8), so as to avoid numerical pseudo-oscillations from the sudden application of a large amplitude displacement.

Figure 10 compares analytical with numerical strain amplitude predictions. Absolute rather than algebraic values of strains are presented again, in order to simplify the comparison. It may be observed that the analytical relations predict with reasonable accuracy the peak values, as well as the distribution of strain amplitudes over the entire cross section of the shell. Observed differences are rather small, and can be attributed to the low $C_{S} / C_{R}$ ratio (i.e. $\left.C_{S} / C_{R}=0.275\right)$ and the low $\alpha_{R}$ angle considered in the analysis, which are close to the limits of application of the analytical solutions for soft soil over bedrock. In a similar analysis, not shown here for reasons of briefness, where the shear wave velocity ratio was decreased to $C_{S} / C_{R}=0.09$ the differences between the analytical and the numerical predictions practically diminished.

\section{Design strains}

Uniform ground conditions.- Seismic strain amplitudes derived previously were expressed as functions of the following angles: the angle of incidence $\varphi$, the angle of motion vector $\beta$, and the polar angle $\theta$. In order to conclude to a set of design seismic strains, which should be superimposed 
to strains resulting from various static loads, the analytical expressions must be properly maximized with respect to the above unknown angles, which form the random problem variables, as they cannot be a priori known. A strict mathematical maximization procedure is rather cumbersome, as it has to account simultaneously for all independent random problem variables, and consequently maximization of strains was accomplished numerically. In more detail, the strain amplitudes were normalized against $\varepsilon_{o}=V_{\max } / C$, their values were computed numerically for a total of equally spaced 90x360x90 combinations of input $\varphi, \theta$ and $\beta$ values, and the peak was identified as the design strain. Angles $\varphi$ and $\beta$ varied in the $0 \div \pi / 2$ range while angle $\theta$ varied in the $0 \div 2 \pi$ range.

The same methodology is applied for the computation of the principal (major and minor):

$\varepsilon_{1,3}=\frac{\varepsilon_{a}+\varepsilon_{h}}{2} \pm \sqrt{\left(\frac{\varepsilon_{a}-\varepsilon_{h}}{2}\right)^{2}+\left(\frac{\gamma}{2}\right)^{2}}$

which represent the maximum normal strain applied to a point, and the von Mises strain amplitudes:

$\varepsilon_{v M}=\frac{1}{1+v_{l}} \sqrt{\varepsilon_{a}^{2}+\varepsilon_{h}^{2}-\varepsilon_{a} \varepsilon_{h}+\frac{3}{4} \gamma^{2}}$

which is mostly employed in failure criteria for steel pipelines. However, note that these seismic strain measures are merely indicative of the relative magnitude of seismic strains, and have been computed for the sake of comparison with the respective normal and shear strain components. In actual design practice their computation should also take into account strains from static load combinations (e.g. self-weight, soil overburden load, internal pressure).

In summary, the resulting design seismic strain amplitudes are given in Table 1. To compare with current design practice, Table 1 also lists the analytical relations of St. John and Zahrah [15] which form the basis of design guidelines for buried pipelines [6, 28] and tunnels [7] today. It is reminded that these relations apply strictly to maximum axial $\left(\varepsilon_{a}\right)$, hoop $\left(\varepsilon_{h}\right)$ and shear $(\gamma)$ strains. Thus, the principal $\left(\varepsilon_{1}, \varepsilon_{3}\right)$ and von Mises $\left(\varepsilon_{v M}\right)$ strains appearing (in brackets) in the same column were approximately evaluated by superposition of the corresponding maximum normal and shear 
components, despite the fact that they are not concurrent on the cross section, while ignoring strains due to static loads for the sake of comparison.

Note that, since the direction of wave propagation is random, the peak particle velocity $V_{\max }$ that is used in the computation of design strains in Table 1 corresponds to the maximum amplitude of the 3-D resultant of motion on the ground surface, which is equal to:

$V_{\max }=\max \sqrt{V_{L}^{2}+V_{T}^{2}+V_{V}^{2}}$

where $V_{L}, V_{T}$ and $V_{V}$ are the velocity time history components of the seismic motion in any two horizontal and the vertical direction. However, actual seismic recordings show that the above 3-D peak particle velocity is, more or less, equal to the peak particle velocity of the stronger component of the recorded motion, i.e.

$V_{\text {max }} \approx \max \left(V_{L, \text { max }}, V_{V, \text { max }}, V_{T, \text { max }}\right)$

The first thing to observe in Table 1 is that the maximum principal strain $\left(\varepsilon_{l}\right)$ and the von Mises strain $\left(\varepsilon_{v M}\right)$ predicted by the new relations for seismic wave action exclusively are about $42 \%$ to $74 \%$ higher than the axial and the hoop strain components which form the basis for design today. This observation has little practical significance for buried pipelines with peripheral joints, as long as these joints have reduced strength relative to the pipeline material and consequently they will fail under the action of axial strain $\varepsilon_{\alpha}$. However, they suggest that in all other cases (e.g. continuous tunnels or steel pipelines with spiral welding) seismic design should be based on $\varepsilon_{1}$ and $\varepsilon_{v M}$, rather than on $\varepsilon_{\alpha}$ and $\varepsilon_{h}$.

Comparison with the St. John and Zahrah relations shows further that the widely used approximate procedure to predict seismic strains in the structure from free field ground strains is accurate as far as the normal (axial $\varepsilon_{\alpha}$ and hoop $\varepsilon_{h}$ ) and the shear strains are concerned. Nevertheless, this procedure is used to compute the major principal and the von Misses strains $\left(\varepsilon_{l}\right.$ and $\left.\varepsilon_{v M}\right)$, the proposed design values are overestimated by $41 \%$ and $15 \%$ respectively.

Soft soil over bedrock. - In this case, the random problem variables become four, as the angle of incidence at the soil-bedrock interface $\left(\alpha_{R}=0 \div \pi / 2\right)$ should also be accounted for. Using a variation of the computer code written for the simultaneous maximization of strains for the uniform ground 
case, the maximum design strains are computed as functions of the $C_{S} / C_{R}$ ratio, and accordingly drawn in Figure 11.

All data can be fitted with reasonable accuracy by simple linear relations, which are listed in Table 2. Furthermore, Table 3 lists the design strains computed herein for a typical case with $C_{S} / C_{R}=1 / 5$, and compares them to analytical strain predictions based on St. John and Zahrah [15]. As the latter refer strictly to uniform ground conditions with shear wave velocity equal to $C$, two alternative predictions are considered: the first for $C=C_{R}$ and the second for $C=C_{S}$.

Focusing first upon the proposed design seismic strains, observe that the maximum principal strain $\left(\varepsilon_{l}\right)$ is considerably higher than the axial strain $\left(\varepsilon_{a}\right)$ and approximately the same as the hoop strain $\left(\varepsilon_{h}\right)$. The difference from the axial strain is proportional to the $C_{R} / C_{S}$ ratio, and in the present application it amounts for $500 \%$. On the other hand, the Von Mises strain $\left(\varepsilon_{V M}\right)$ is higher than both $\varepsilon_{\alpha}$ and $\varepsilon_{h}$. In this case also, the differences increase with the $C_{R} / C_{S}$ ratio, and take the values of $820 \%$ and $60 \%$ respectively for the soil and bedrock properties considered in the present application. The second observation is that nearly all design seismic strain components are underpredicted when the St. John and Zahrah relations are used in conjunction with the shear wave velocity of the bedrock, while they are overpredicted when the shear wave velocity of the soft soil is used instead. The differences range between $0 \%$ and $-470 \%$ in the first case and between $400 \%$ and $-14 \%$ in the second.

Finally, a closer examination of Tables 1, 2 and 3 reveals that solutions derived for uniform ground may be approximately used for structures in soft soil over bedrock as well, under one condition: axial strains $\left(\varepsilon_{\alpha}\right)$ are computed based on the shear wave velocity of the bedrock, while hoop $\left(\varepsilon_{h}\right)$ and shear strains $(\gamma)$ are computed from the soft soil shear wave velocity. This finding applies to the relations for uniform ground proposed herein, but also for the different approximate relations developed earlier.

In summary, it appears that the presence of soft soil in the vicinity of the structure has a significant effect on all seismic strain components that cannot be predicted when using the shear wave propagation velocity of the bedrock. The aforementioned effects apply both to continuous and 
segmented structures, with peripheral joints, and increase as the shear wave velocity contrast between the bedrock and the soil cover becomes larger.

\section{Conclusions}

A 3-D thin shell strain analysis has been presented, regarding long cylindrical underground structures (buried pipelines and tunnels) subjected to seismic shear (S) wave excitation. Similarly to the majority of analytical solutions used today (e.g. $[7,12,13,15])$, inertia and kinematic soilstructure interaction effects are neglected, while seismic waves are assumed to be harmonic, propagating with a plane front. Two distinct cases were considered, namely "uniform ground" and "soft soil over bedrock". Note that, currently available solutions apply strictly to uniform ground conditions, and draw upon free field strains to compute peak normal and shear strains only in the structure section.

In general terms, two are the major gains from the previous investigation. The first is to derive a set of analytical solutions for the distribution over the entire structure section of the normal (axial and hoop) and the shear strain components, that can be used for the calculation of their principal and von Misses counterparts. The second gain is to take into account the effect of soft soil conditions on seismic strains in a systematic way, and clarify the use of an apparent bedrock velocity of wave propagation that is recommended by currently applied design guidelines $[6,28]$. The derived solutions allow a consistent seismic analysis of continuous, as well as, segmented cylindrical underground structures, under various ground conditions.

In more practical terms, it has been shown that, for structures in "uniform ground":

(a) The maximum principal $\left(\varepsilon_{l}\right)$ and the Von Mises $\left(\varepsilon_{v M}\right)$ strains computed with 3-D shell theory for seismic wave action exclusively are $42 \%$ to $74 \%$ higher than the respective axial and hoop strains, which form the basis for design today.

(b) The approximate procedure used to predict structure strains from free field ground strains is justified only for normal (axial and hoop) and shear strains. However, superposition of these peak strains may prove overly conservative, as they do not develop at the same position on the 
cross section. For instance, the seismic major principal strain computed in this way is about $41 \%$ higher than the value computed with the $3-\mathrm{D}$ shell theory.

For structures in "soft soil over bedrock", it is further concluded that:

(c) The maximum seismic principal $\left(\varepsilon_{l}\right)$ and von Mises $\left(\varepsilon_{v M}\right)$ strains computed with the 3-D shell theory are again higher than the respective axial and hoop strain components, only that now the difference is larger. This is especially true for the axial strain where the above difference may reach the same order of magnitude as the shear wave velocity ratio $C_{R} / C_{S}$.

(d) Axial design strains can be indeed predicted from solutions developed for uniform ground, using as input the shear wave velocity of the bedrock. On the contrary, this procedure severely underpredicts the design seismic hoop and shear strains. At first approximation, these strains can be computed using the shear wave velocity of the soft soil instead.

Conclusions (a) and (c) above imply that the seismic design of continuous underground structures (e.g. tunnels or concrete pipelines) or steel pipelines with spiral welding should be based on total (static plus seismic) $\varepsilon_{1}$ and $\varepsilon_{v M}$, rather than on normal strain components $\left(\varepsilon_{a}\right.$ and $\left.\varepsilon_{h}\right)$. This requirement, which admittedly complicates computations, does not apply in the presence of peripheral joints or welds, with reduced strength relative to the pipeline material, which will rather fail under the action of $\varepsilon_{a}$.

The methodology outlined herein is currently extended to P- and Rayleigh waves. In parallel, a systematic analysis of the damages to tunnels and pipelines from Kobe, Chi-Chi and Düzce earthquakes is underway, seeking a quantitative verification of the theoretical findings through well documented case studies.

\section{Acknowledgements}

This research is partially supported by "EPEAEK II-Pythagoras" grant, co-funded by the European Social Fund and the Hellenic Ministry of Education. Professor G. Gazetas of NTUA offered valuable comments as member of the Doctoral Thesis Committee of the first author. These contributions are gratefully acknowledged. 


\section{Appendix: Nomenclature}

$\begin{array}{ll}A_{\max }: & \text { peak particle displacement of the seismic motion } \\ C: & \text { wave propagation velocity in uniform ground } \\ C_{R}: & \text { wave propagation velocity in bedrock } \\ C_{S}: & \text { wave propagation velocity in soft soil } \\ D: & \text { diameter of the underground structure } \\ E_{l}: & \text { Young's modulus of the structure material } \\ E_{m}: & \text { Young's modulus of the soil medium } \\ F: & \text { flexibility ratio } \\ L: & \text { wavelength in uniform ground } \\ L_{R}: & \text { wavelength in bedrock } \\ L_{S}: & \text { wavelength in soft soil } \\ t: & \text { time } \\ t_{s}: & \text { thickness of the cross-section } \\ T: & \text { harmonic wave period } \\ u: & \text { displacement } \\ \alpha_{m a x}: & \text { peak particle acceleration of the seismic motion } \\ \alpha_{R}: & \text { angle of incidence in the soft soil-bedrock interface } \\ \alpha_{S}: & \text { angle of propagation in the soft soil layer } \\ \beta: & \text { angle formed by the peak particle velocity vector and the propagation plane } \\ \gamma: & \text { shear strain } \\ \gamma_{l}: & \text { specific weight of the structure material } \\ \varepsilon_{\alpha}: & \text { axial strain } \\ \varepsilon_{h}: & \text { hoop strain } \\ \varepsilon_{v M}: & \text { von Mises strain } \\ \varepsilon_{l, 3}: & \text { principal strains } \\ \theta: & \text { polar angle in the cylindrical coordinate system of the cross-section } \\ \theta_{x y}: & \text { Eulerian angle of rotation of coordinate system axis } \\ \theta_{x, i}: & \text { rotation } \\ v_{m}: & \text { Poisson's ratio of the soil medium } \\ v_{l}: & \text { Poisson's ratio of the structure material } \\ \varphi: & \text { angle of incidence in the wave-structure plane }\end{array}$

\section{References}

1. EQE Summary Report. The January 17, 1995 Kobe Earthquake, 1995.

2. Sinozuka M. The Hanshin-Awaji earthquake of January 17, 1995: Performance of lifelines. NCEER-95-0015 1995.

3. Chen WW, Shih B-J, Chen Y-C, Hung J-H, Hwang HH. Seismic response of natural gas and water pipelines in the Ji-Ji earthquake. Soil Dynamics and Earthquake Engineering 2002;22:1209-1214.

4. Wang WL, Wang TT, Su JJ, Lin CH, Seng CR, Huang TH. Assessment of damage in mountain tunnels due to the Taiwan Chi-Chi earthquake. Soil Dynamics and Earthquake Engineering 2002;22:73-96.

5. Uenishi K, Sakurai S, Uzarski SM-J, Arnold C. Chi-Chi, Taiwan, earthquake of September 21, 1999: Reconnaissance report. Earthquake Spectra 1999;5(19):153-173.

6. European Committee for Standardization (CEN). Eurocode 8: Design of structures for earthquake resistance-Part 4: Silos, tanks and pipelines. Draft No 2, December 2003.

7. Wang JJ. Seismic design of tunnels. Parsons Brinckerhoff monograph 7, 1993. 
8. Hashash YMA, Hook JJ, Schmidt B, Yao JC. Seismic design and analysis of underground structures. Tunnelling and Underground Space Technology 2001;16:247-293.

9. Hoeg K. Stresses against underground structural cylinders. Journal of the Soil Mechanics and Foundation Division, ASCE 1968; Vol. 94, SM4.

10. Hendron AJ Jr, Fernandez G. Dynamic and static considerations for underground chambers. In: Seismic Design of Embankments and Caverns. New York, 1983, pp 157-197.

11. O'Rourke MJ, Liu X. Response of buried pipelines subject to earthquake effects. Monograph Series MCEER, 1999.

12. Newmark NM. Problems in wave propagation in soil and rock. In: University of New Mexico Press. Proceedings of the International Symposium on Wave Propagation and Dynamic Properties of Earth Materials. Albuquerque NM, 1968, pp 7-26.

13. Kuesel TR. Earthquake design criteria for subways. Journal of Structural Division, ASCE 1969;ST6:1213-1231.

14. Yeh GCK. Seismic analysis of slender buried beams. Bulletin of the Seismological Society of America 1974; Vol. 64 No 5:1551-1562.

15. St. John CM, Zahrah TF. Aseismic design of underground structures. Tunnelling and Underground Space Technology 1987; Vol. 2 No. 2:165-197.

16. Datta SK, O'Leary PM, Shah AH. Three-dimensional dynamic response of buried pipelines to incident longitudinal and shear waves. J. Appl. Mech. ASME 1985;52:919-926.

17. Wong KC, Datta SK, Shah AH. Three-dimensional motion of buried pipeline I: Analysis, II: Numerical results. J. Eng. Mech. ASCE 1986;112:1319-1337 \& 1338-1345.

18. Liu SW, Datta SK, Khair KR, Shah AH. Three-dimensional dynamics of pipelines buried in backfilled trenches due to oblique incidence of body waves. Soil Dynamics and Earthquake Engineering 1991;10:182-191.

19. Luco JE, de Barros FCP. Seismic response of a cylindrical shell embedded in a layered viscoelastic half space. I: Formulation; II: Validation and numerical results. Earthquake Engineering and Structural Dynamics 1994;23:553-567 \& 569-580.

20. Ogawa Y, Koike T. Structural design of buried pipelines for severe earthquakes. Soil Dynamics and Earthquake Engineering 2001;21:199-209.

21. O' Rourke MJ, El Hmadi KE. Analysis of continuous buried pipelines for seismic wave effects. Earthquake Engineering and Structural Dynamics 1988;110:917-929.

22. Manolis GD, Beskos DE. Underground and lifeline structures. In: Computer Analysis and Design of Earthquake Resistant Structures: A Handbook. D.E. Beskos and S.A. Anagnostopoulos, Editors, CMP, Southampton, 1997, pp. 775-837.

23. Stamos AA, Beskos DE. Dynamic analysis of large 3D underground structures by the BEM. Earthquake Engineering and Structural Dynamics 1995;24:917-934.

24. Stamos AA, Beskos DE. 3-D seismic response analysis of long lined tunnels in halfspace. Soil Dynamics and Earthquake Engineering 1996;15:111-118.

25. Manolis GD, Talaslidis DG, Tetepoulidis PI, Apostolidis G. Soil structure interaction analyses for buried pipelines. In: Advances in Simulation and Interaction Techniques. M. Papadrakakis and B.H.V. Topping, Editors, Civil-Comp, Edinburgh, 1994.

26. Manolis GD, Pitilakis K, Tetepoulidis PI, Mavridis G. A hierarchy of numerical models for SSI analysis of buried structures. In: Soil Dynamics and Earthquake Engineering VII. A.S. Cakmak and C.A. Brebbia, Editors, CMP, Southampton, 1995.

27. Manolis GD, Tetepoulidis PI, Talaslidis DG, Apostolidis G. Seismic analysis of buried pipeline in a 3D soil continuum. Engineering Analysis with Boundary Elements 1995;15:371-394. 
28. American Lifelines Alliance. Guidelines for the design of buried steel pipes; ASCE, 2001. 29. Ansys Inc. ANSYS Release 8.0 Documentation 2003. 


\section{Tables}

Table 1.

Maximum normalized seismic strains for underground structures in uniform ground.

\begin{tabular}{ccc}
\hline Strain component & Design value & St. John and Zahrah [15] \\
\hline$\varepsilon_{\alpha} /\left(\mathrm{V}_{\max } / \mathrm{C}\right)$ & 0.50 & 0.50 \\
$\gamma /\left(\mathrm{V}_{\max } / \mathrm{C}\right)$ & 1.00 & 1.00 \\
$\varepsilon_{\mathrm{h}} /\left(\mathrm{V}_{\max } / \mathrm{C}\right)$ & 0.50 & 0.50 \\
$\varepsilon_{\mathrm{VM}} /\left(\mathrm{V}_{\max } / \mathrm{C}\right)$ & $0.87 /\left(1+v_{1}\right)$ & {$\left[1.00 /\left(1+v_{1}\right)\right]^{1}$} \\
$\varepsilon_{1} /\left(\mathrm{V}_{\max } / \mathrm{C}\right)$ & 0.71 & {$[1.00]^{1}$} \\
$\varepsilon_{3} /\left(\mathrm{V}_{\max } / \mathrm{C}\right)$ & -0.71 & {$[-1.00]^{1}$} \\
\hline
\end{tabular}

(T) Computed from superposition of the respective $\varepsilon_{a}$, $\varepsilon_{h}$ and $\gamma$.

Table 2.

Maximum normalized seismic strains for underground structures in soft soil.

\begin{tabular}{cc}
\hline Strain component & Design value \\
\hline$\varepsilon_{\alpha} /\left(\mathrm{V}_{\max } / \mathrm{C}_{\mathrm{S}}\right)$ & $0.5 \cdot \mathrm{C}_{\mathrm{S}} / \mathrm{C}_{\mathrm{R}}$ \\
$\gamma /\left(\mathrm{V}_{\max } / \mathrm{C}_{\mathrm{S}}\right)$ & $0.43 \cdot \mathrm{C}_{\mathrm{S}} / \mathrm{C}_{\mathrm{R}}+0.98$ \\
$\varepsilon_{\mathrm{h}} /\left(\mathrm{V}_{\max } / \mathrm{C}_{\mathrm{S}}\right)$ & $0.36 \cdot \mathrm{C}_{\mathrm{S}} / \mathrm{C}_{\mathrm{R}}+0.5$ \\
$\varepsilon_{\mathrm{vM}} /\left(\mathrm{V}_{\max } / \mathrm{C}_{\mathrm{S}}\right)$ & {$\left[0.38 \cdot \mathrm{C}_{\mathrm{S}} / \mathrm{C}_{\mathrm{R}}+0.85\right] /\left(1+v_{1}\right)$} \\
$\varepsilon_{1} /\left(\mathrm{V}_{\max } / \mathrm{C}_{\mathrm{S}}\right)$ & $0.5 \cdot \mathrm{C}_{\mathrm{S}} / \mathrm{C}_{\mathrm{R}}+0.5$ \\
$\varepsilon_{3} /\left(\mathrm{V}_{\max } / \mathrm{C}_{\mathrm{S}}\right)$ & $-0.5 \cdot \mathrm{C}_{\mathrm{S}} / \mathrm{C}_{\mathrm{R}}-0.5$ \\
\hline
\end{tabular}

Table 3.

Comparison of design seismic strains and strains proposed by St. John and Zahrah [15] for $\mathrm{C}_{\mathrm{S}} / \mathrm{C}_{\mathrm{R}}=1 / 5$

\begin{tabular}{cccc}
\hline \multirow{2}{*}{ Strain component } & \multirow{2}{*}{ Design value } & \multicolumn{2}{c}{ St. John and Zahrah [15] } \\
& for $\mathrm{C}=\mathrm{C}_{\mathrm{R}}$ & for $\mathrm{C}=\mathrm{C}_{\mathrm{S}}$ \\
\hline$\varepsilon_{\alpha} /\left(\mathrm{V}_{\max } / \mathrm{C}_{\mathrm{S}}\right)$ & 0.10 & 0.10 & 0.50 \\
$\gamma /\left(\mathrm{V}_{\max } / \mathrm{C}_{\mathrm{S}}\right)$ & 1.06 & 0.20 & 1.00 \\
$\varepsilon_{\mathrm{h}} /\left(\mathrm{V}_{\max } / \mathrm{C}_{\mathrm{S}}\right)$ & 0.57 & 0.10 & 0.50 \\
$\varepsilon_{\mathrm{vM}} /\left(\mathrm{V}_{\max } / \mathrm{C}_{\mathrm{S}}\right)$ & $0.92 /\left(1+v_{1}\right)$ & {$\left[0.20 /\left(1+v_{1}\right)\right]^{1}$} & {$\left[1 /\left(1+v_{1}\right)\right]^{1}$} \\
$\varepsilon_{1} /\left(\mathrm{V}_{\max } / \mathrm{C}_{\mathrm{S}}\right)$ & 0.60 & {$[0.20]^{1}$} & {$[1.00]^{1}$} \\
$\varepsilon_{3} /\left(\mathrm{V}_{\max } / \mathrm{C}_{\mathrm{S}}\right)$ & -0.60 & {$[-0.20]^{1}$} & {$[-1.00]^{1}$} \\
(1) Computed from superposition of the respective $\varepsilon_{a}, \varepsilon_{h}$ and $\gamma$. & &
\end{tabular}




\section{Figure Captions}

Fig. 1. Propagation of a shear wave in a plane randomly oriented relatively to the structure axis.

Fig. 2. Strains in underground structures modeled as thin-walled cylindrical shells.

Fig.3. Vectorial analysis of an obliquely impinging wave into two apparent waves: one propagating along and the other propagating transversely to the undeformed structure axis.

Fig. 4. Definition of the coordinate system for the calculation of strains due the propagation of (a) an oblique SH wave and (b) an oblique SV wave.

Fig. 5. Effect of interface friction on structure displacements: (a) rough interface, (b) smooth interface model.

Fig. 6. Analysis of a wave refracted at the soft soil-bedrock interface into a vertical and a horizontal apparent wave.

Fig. 7. Variation of $\sin \alpha_{S}$ with the angle $\alpha_{R}$, for different values of the $C_{S} / C_{R}$ ratio.

Fig. 8. Mesh discretisation of the 3-D numerical model, presented together with the dynamically imposed displacements at a random node, for the uniform ground analysis (this figure is out of scale).

Fig. 9. Comparison of analytical and numerical results along a random cross-section for a uniform ground case.

Fig. 10. Comparison of analytical and numerical results along a random cross-section for a soft soil over bedrock case.

Fig. 11. Variation of strain amplitudes with the $C_{S} / C_{R}$ ratio, for underground structures in soft soil: (a) axial, shear and hoop strains, (b) principal and von Mises strains. 


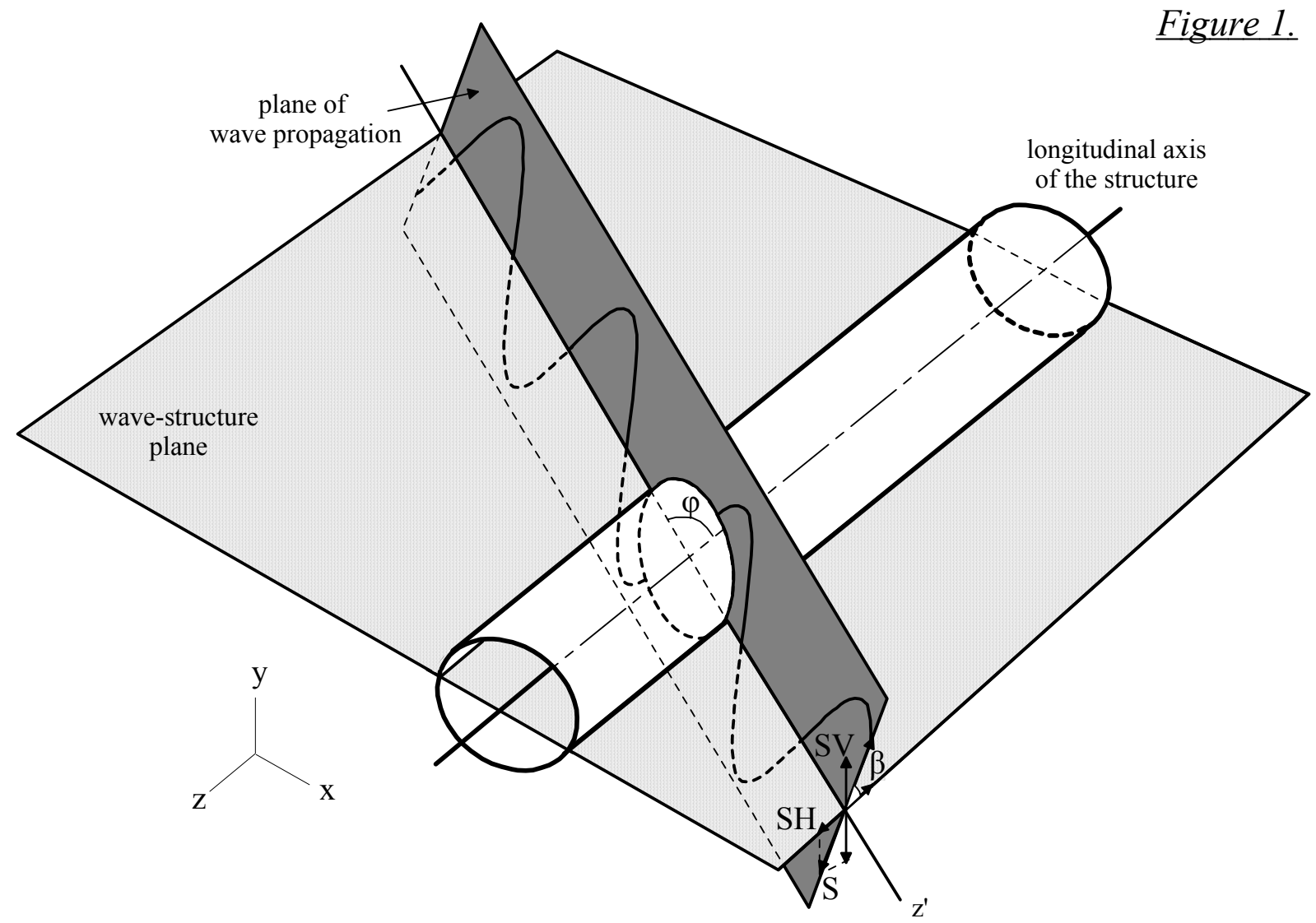

Figure 2.

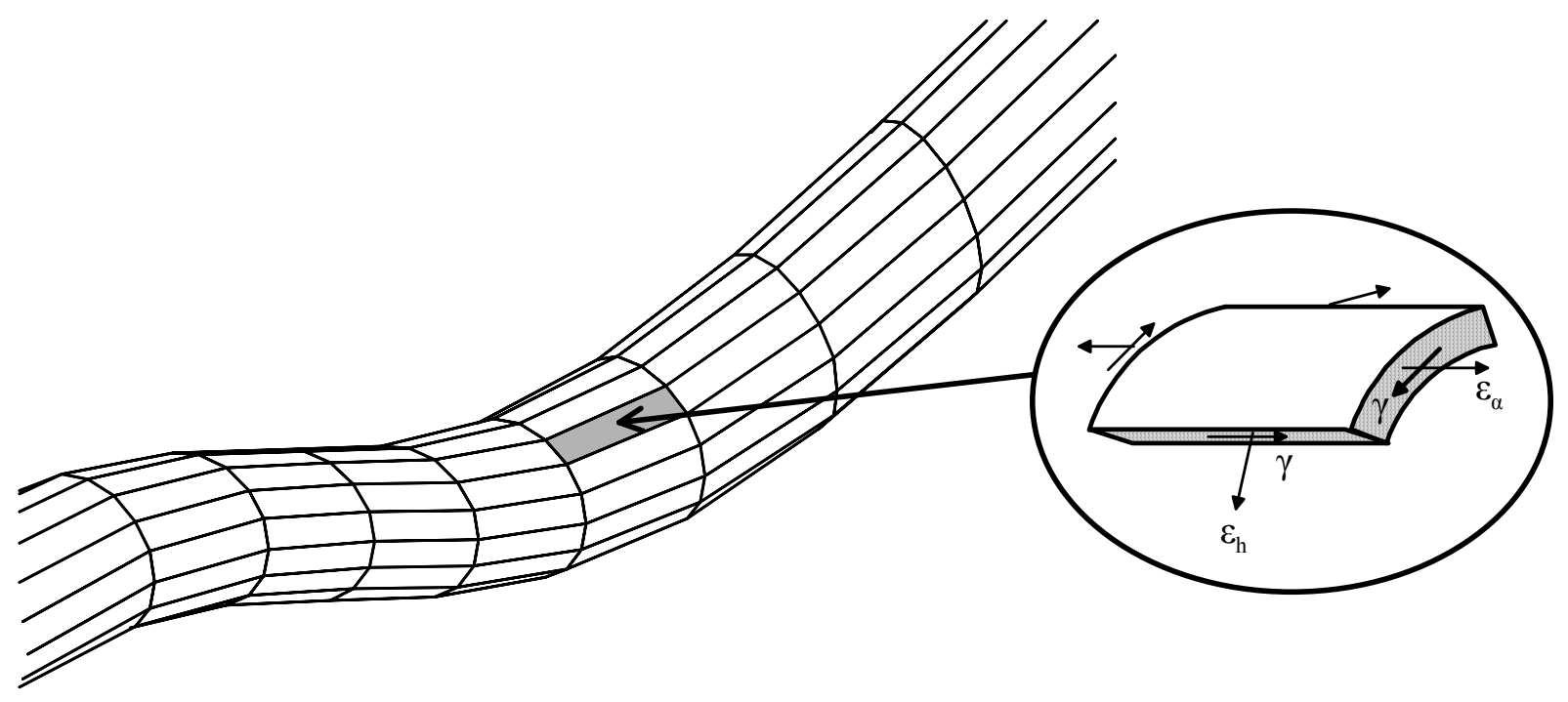




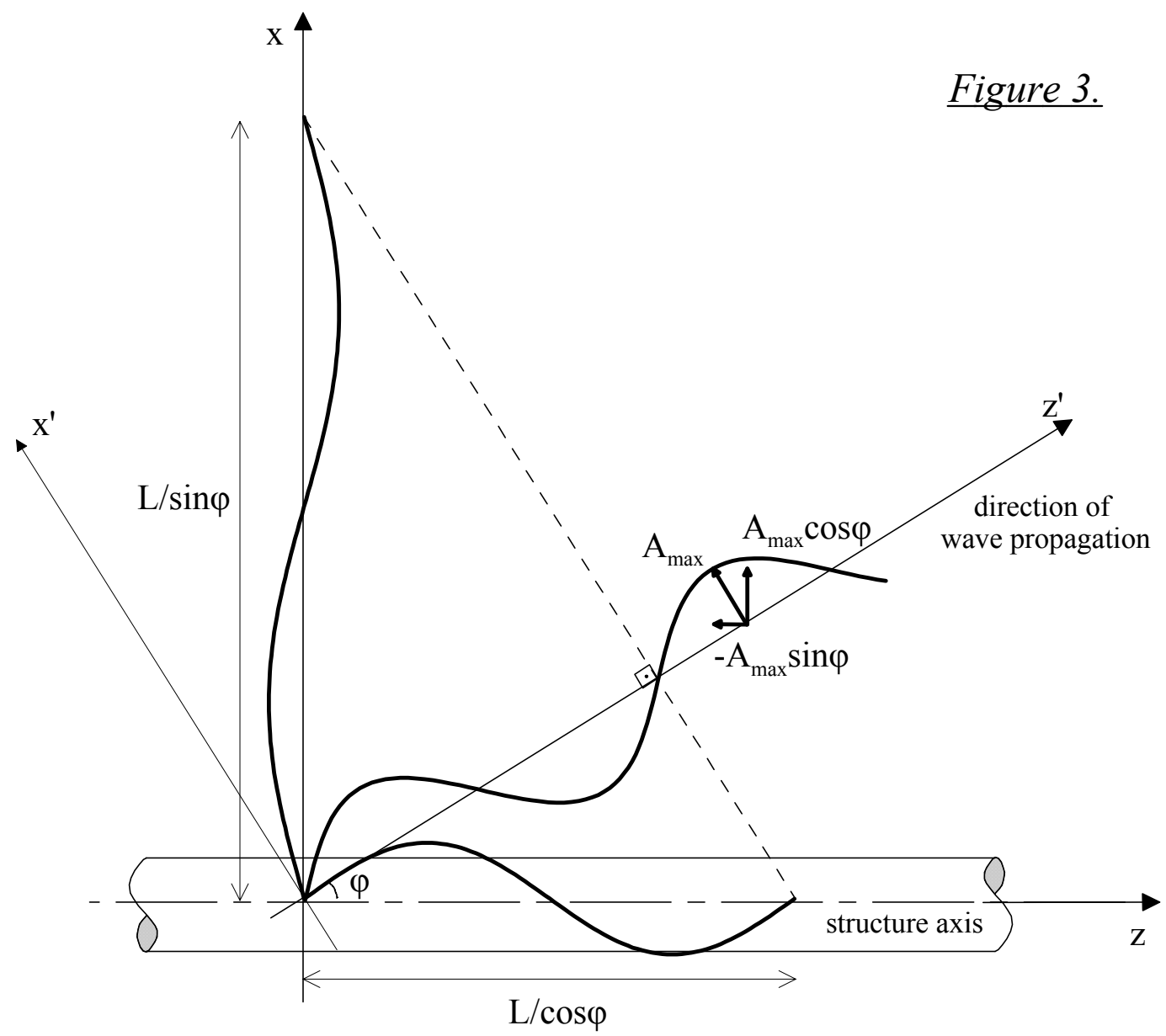

Figure 4.
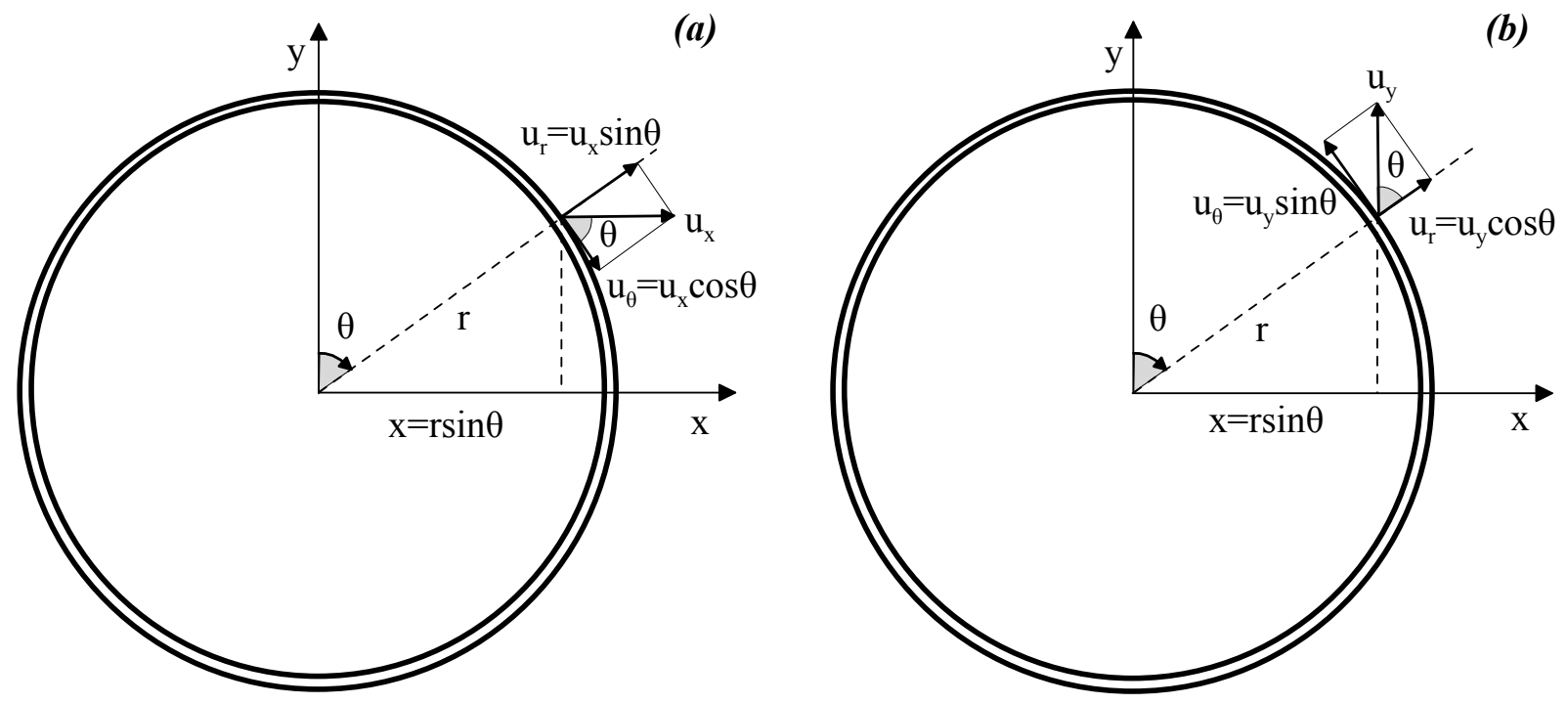
Figure 5.
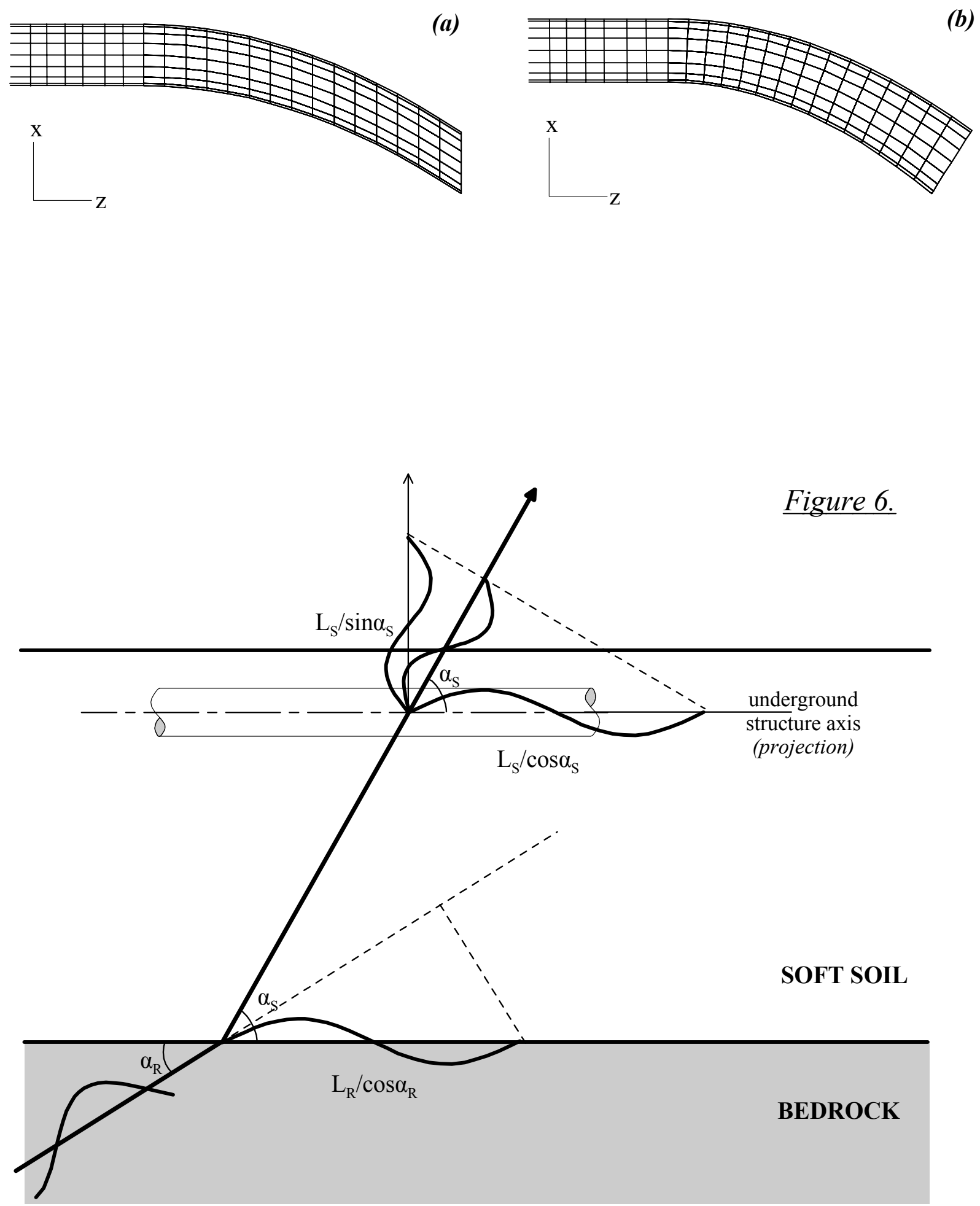


\section{Figure 7.}

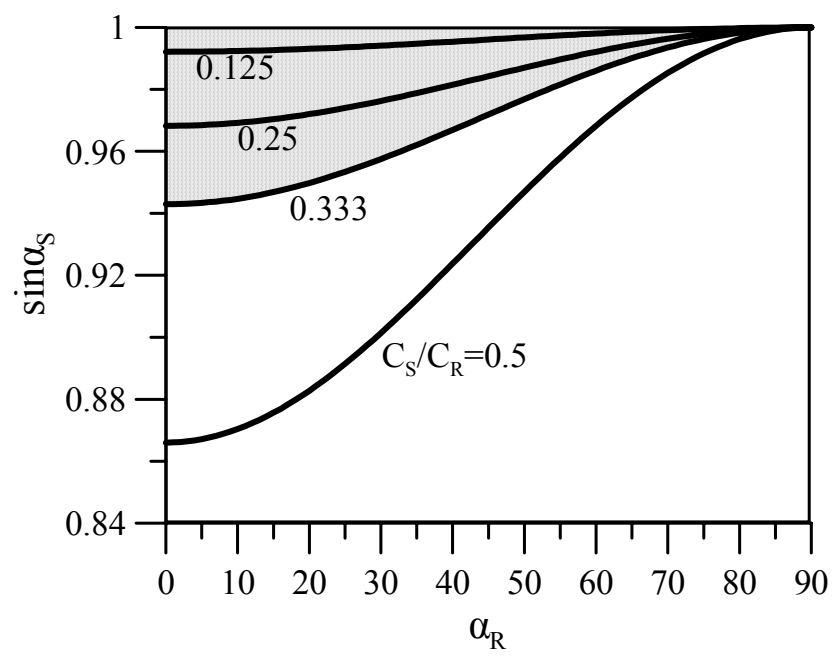

Figure 8.

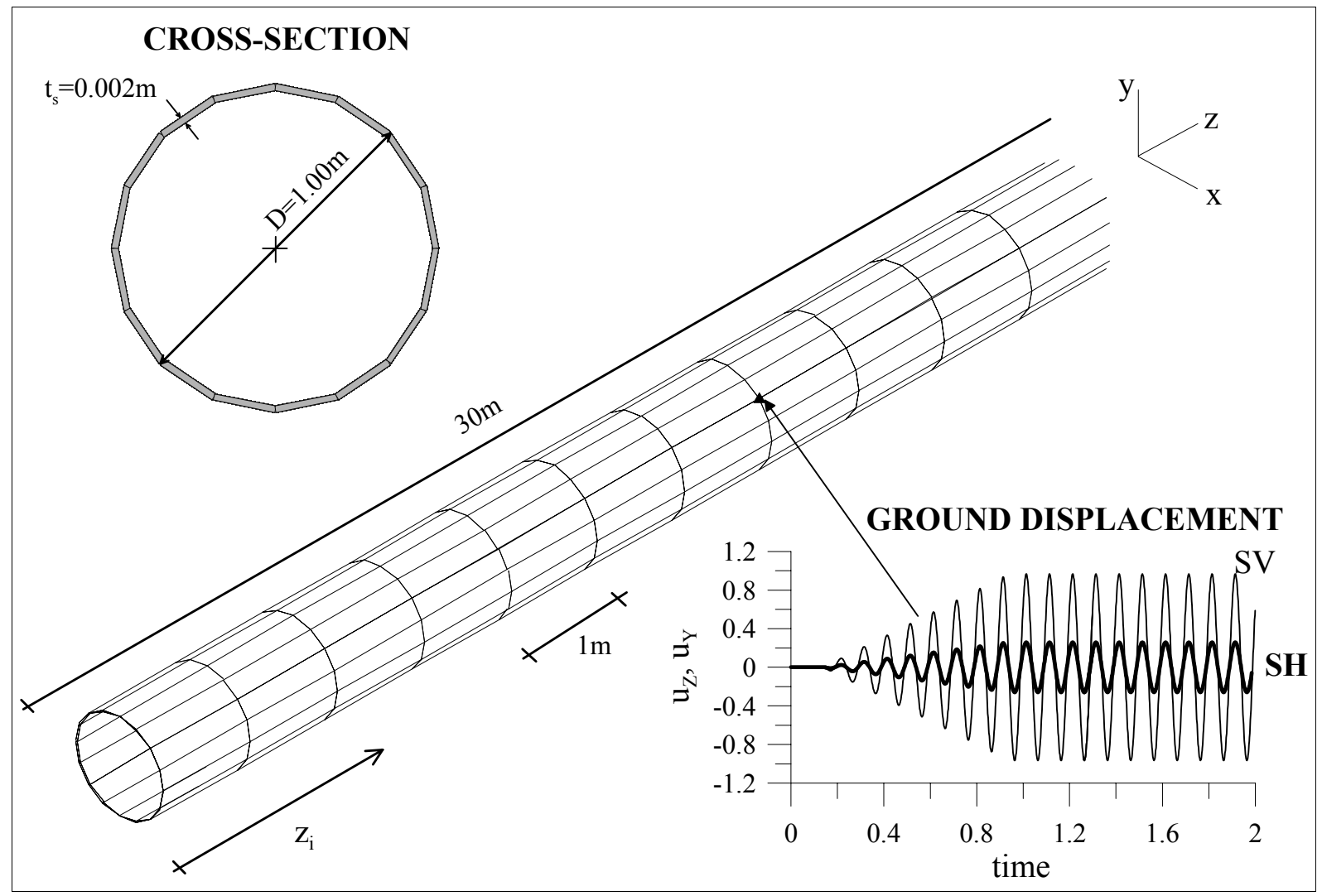


Figure 9.
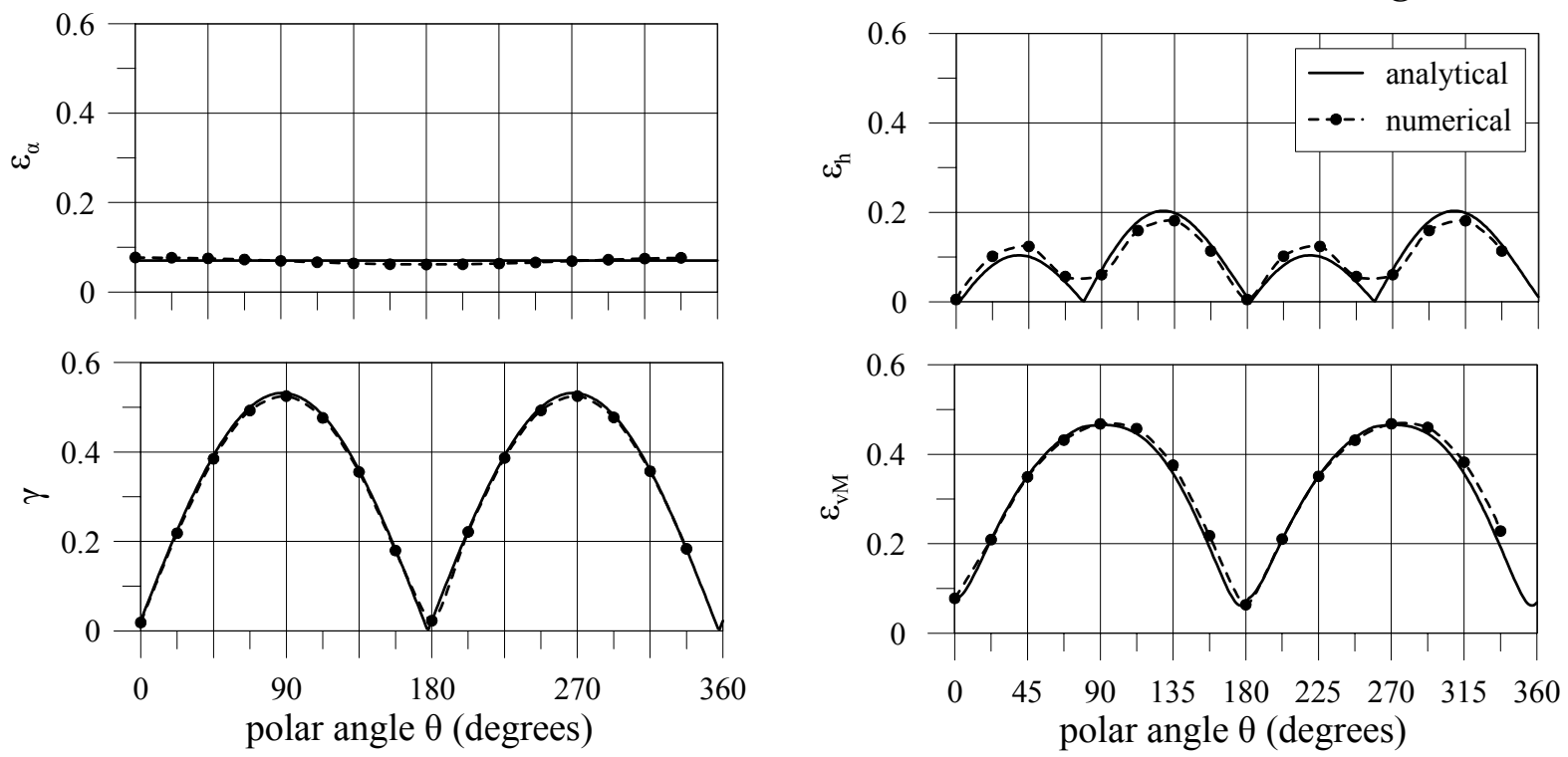

Figure 10.
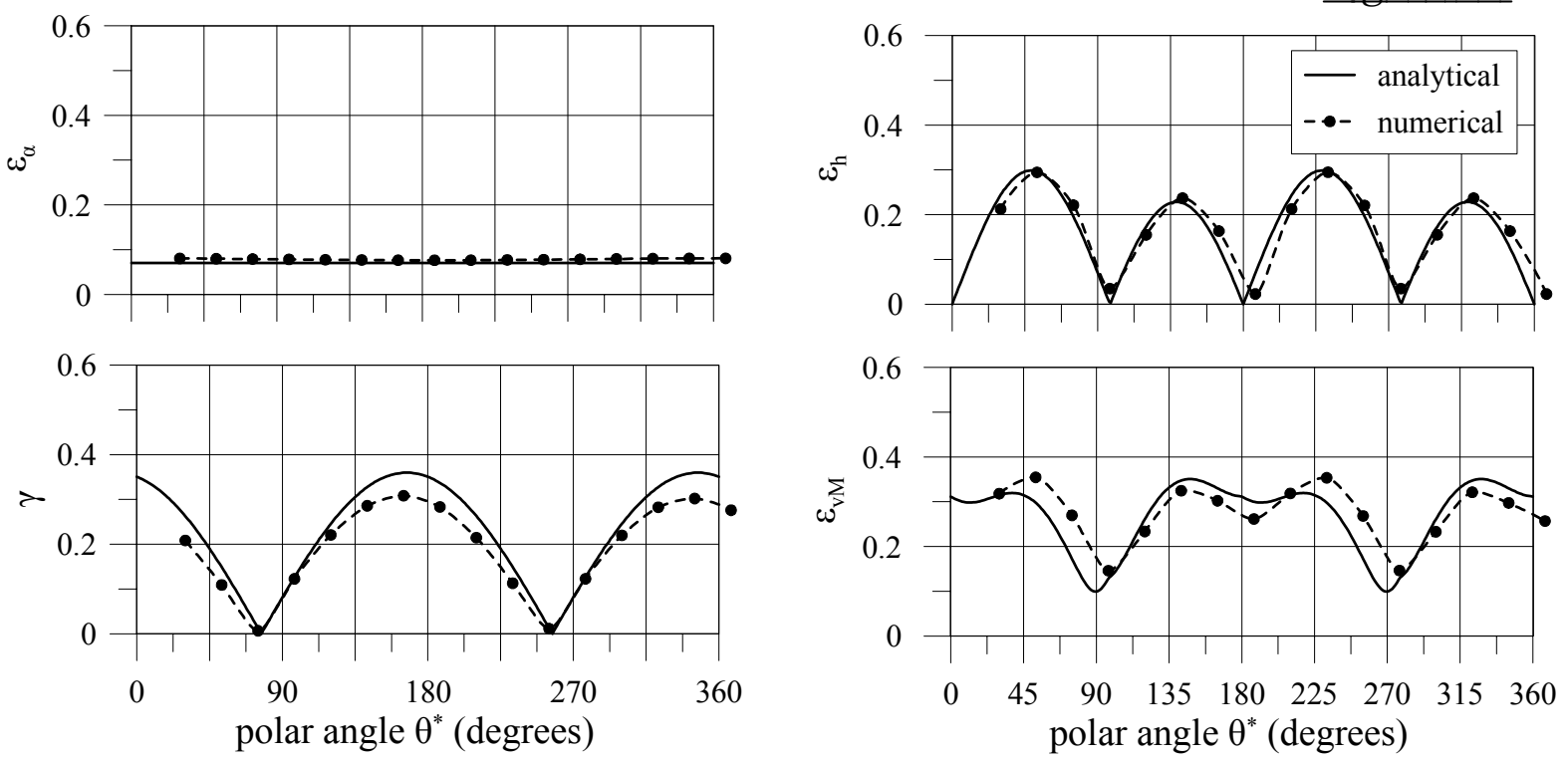
Figure 11.
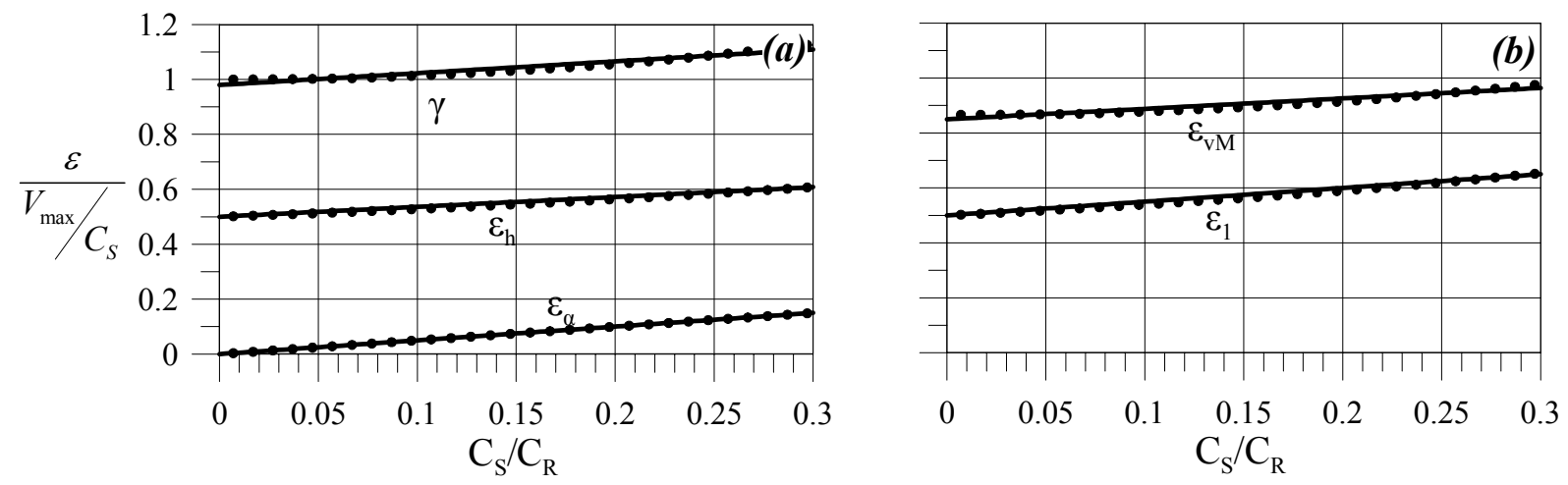